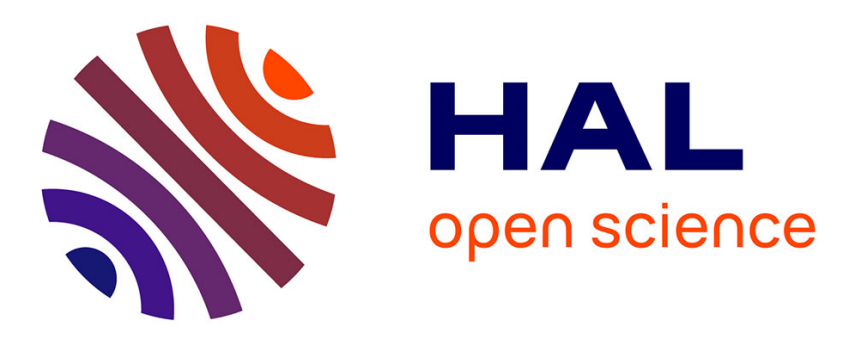

\title{
Caffeine intake during pregnancy, late miscarriage and stillbirth
}

\author{
Darren C. Greenwood, Nisreen Alwan, Sinead Boylan, Janet E. Cade, Jim
}

Charvill, Karen C. Chipps, Marcus S. Cooke, Vivien A. Dolby, Alastair W. M. Hay, Shabira Kassam, et al.

\section{To cite this version:}

Darren C. Greenwood, Nisreen Alwan, Sinead Boylan, Janet E. Cade, Jim Charvill, et al.. Caffeine intake during pregnancy, late miscarriage and stillbirth. European Journal of Epidemiology, 2010, 25 (4), pp.275-280. 10.1007/s10654-010-9443-7 . hal-00578458

\section{HAL Id: hal-00578458 https://hal.science/hal-00578458}

Submitted on 21 Mar 2011

HAL is a multi-disciplinary open access archive for the deposit and dissemination of scientific research documents, whether they are published or not. The documents may come from teaching and research institutions in France or abroad, or from public or private research centers.
L'archive ouverte pluridisciplinaire HAL, est destinée au dépôt et à la diffusion de documents scientifiques de niveau recherche, publiés ou non, émanant des établissements d'enseignement et de recherche français ou étrangers, des laboratoires publics ou privés. 


\title{
Caffeine intake during pregnancy, late miscarriage and stillbirth
}

\author{
Darren C. Greenwood - Nisreen Alwan - Sinead Boylan · Janet E. Cade • \\ Jim Charvill - Karen C. Chipps $\cdot$ Marcus S. Cooke - Vivien A. Dolby • \\ Alastair W. M. Hay · Shabira Kassam • Sara F. L. Kirk · Justin C. Konje • \\ Neelam Potdar · Susan Shires • Nigel Simpson • Nicholas Taub • \\ James D. Thomas $\cdot$ James Walker $\cdot$ Kay L. M. White $\cdot$ Christopher P. Wild
}

Received: 14 December 2009/Accepted: 8 March 2010/Published online: 21 March 2010

(C) Springer Science+Business Media B.V. 2010

\begin{abstract}
Caffeine is a commonly consumed drug during pregnancy with the potential to affect the developing fetus. Findings from previous studies have shown inconsistent results. We recruited a cohort of 2,643 pregnant women, aged 18-45 years, attending two UK maternity units between 8 and 12 weeks gestation from September 2003 to June 2006. We used a validated tool to assess caffeine intake at different stages of pregnancy and related this to late miscarriage and stillbirth, adjusting for confounders, including salivary cotinine as a biomarker of smoking status. There was a strong association between caffeine intake in the first trimester and subsequent late miscarriage and stillbirth, adjusting for confounders. Women whose pregnancies resulted in late miscarriage or stillbirth had higher caffeine intakes (geometric mean $=145 \mathrm{mg} /$ day; 95\% CI: 85-249) than those with live births (103 mg/day; 95\% CI: 98-108). Compared to those consuming $<100 \mathrm{mg} /$ day, odds ratios increased to 2.2 (95\% CI: 0.7-7.1) for 100-199 mg/day, 1.7
\end{abstract}

All the authors are the members of CARE study group and see the Appendix for the contribution to authorship.

D. C. Greenwood $(\square) \cdot$ N. Alwan · S. Boylan ·

J. E. Cade · V. A. Dolby - A. W. M. Hay ·

S. F. L. Kirk · S. Shires · N. Simpson

J. D. Thomas - J. Walker - K. L. M. White

Biostatistics Unit, Centre for Epidemiology and Biostatistics,

University of Leeds, Worsley Building, Leeds LS2 9JT,

United Kingdom

e-mail: d.c.greenwood@leeds.ac.uk

J. Charvill - K. C. Chipps - M. S. Cooke - S. Kassam ·

J. C. Konje · N. Potdar · N. Taub

University of Leicester, Leicester, LE2 7LX, United Kingdom

C. P. Wild

International Agency for Research on Cancer, Lyon, France
(0.4-7.1) for 200-299 mg/day, and 5.1 (1.6-16.4) for 300+ $\mathrm{mg} /$ day $\left(P_{\text {trend }}=0.004\right)$. Greater caffeine intake is associated with increases in late miscarriage and stillbirth. Despite remaining uncertainty in the strength of association, our study strengthens the observational evidence base on which current guidance is founded.

Keywords Caffeine $\cdot$ Miscarriage $\cdot$ Still birth
Abbreviations
CI Confidence interval
IQR Interquartile range
OR Odds ratio
SD Standard deviation

\section{Introduction}

Caffeine is a commonly consumed drug during pregnancy with the potential to affect the developing foetus [1-3]. Cohort studies have shown that maternal caffeine intake may be associated with decreased birth weight and fetal growth restriction, [4, 5] though not consistently [6]. The only trial conducted suggested no substantial effect of caffeine reduction in the second half of pregnancy [7]. The evidence for caffeine consumption earlier in pregnancy to be a risk factor for miscarriage may be stronger, [8-11] but again there is still uncertainty [12-14] and no large pragmatic effectiveness trials have been conducted. Most guidelines recommend limiting caffeine intake immediately before and during pregnancy as a precaution, [15-18] whilst recognising that the strength of any association is still unclear [19]. 
The inconsistency in results may be attributable to one or more sources of bias, including imprecise estimation of caffeine intake, assuming that coffee or tea are the only sources of caffeine, retrospective measurement of assessment of caffeine consumption, or inadequate control for important confounding factors, especially smoking and alcohol consumption. To contribute to understanding the role of caffeine during pregnancy, using improved methodology, we examined the association of maternal caffeine intake with late miscarriage and intrauterine fetal death (stillbirth), using a highly detailed caffeine assessment tool, previously validated against both a food and drink diary and repeated biomarkers of caffeine intake (salivary caffeine and paraxanthine), to prospectively quantify total caffeine intake, from all possible sources, in the first trimester and throughout pregnancy [20]. We aimed to adequately correct for potentially important confounding from alcohol intake and most importantly from smoking using cotinine as a biomarker in a large cohort of pregnant women.

\section{Methods}

\section{Subjects}

A cohort of 2,643 pregnant women aged 18-45 years with singleton pregnancies attending two large UK teaching hospital maternity units was recruited between September 2003 and June 2006 between 8 and 12 weeks gestation, as described in detail elsewhere [5]. Women with prior chronic disease, psychiatric illness, HIV or hepatitis B infection, were excluded. The demographic details of age, parity, maternal height, weight, socioeconomic status and gestational age were recorded by a questionnaire. Local ethics committee approval was obtained at both centres and written (signed) informed consent was obtained from each volunteer before recruitment.

\section{Outcomes and measurements}

Information regarding antenatal pregnancy complications and delivery details were obtained from the electronic maternity databases. The primary outcome of fetal growth restriction has been reported elsewhere [5]. This paper presents our secondary outcome measure of late miscarriage (spontaneous pregnancy loss between 12 and 24 weeks) and stillbirth (delivery $\geq 24$ weeks with no signs of life at birth).

A validated caffeine assessment tool completed during initial hospital registration at 8-12 weeks recorded habitual caffeine intake, divided into the 4 weeks before pregnancy, weeks $1-4$, and weeks 5-12, repeated again for weeks
13-28, and again for weeks 28-36 weeks or end of pregnancy [20]. The questionnaire covered all potential dietary sources of caffeine, both food and drink, and over the counter medications. Specific brand names, portion sizes, methods of preparation, quantity and frequency of intake were collected for different gestational periods. Precise caffeine intakes were then estimated based on the published caffeine content for each item, [21] and information provided by manufacturers and coffee houses. Alcohol intake was self-reported using a tool developed for the UK Women's Cohort study [22]. Self-reported smoking, nausea and vomiting were also collected.

Women provided saliva samples at recruitment for determining nicotine exposure, collected using a Salivette ${ }^{\circledR}$ (Sarstedt, Aktiengesellschaft \& Co., Loughborough, UK) kept in the mouth for 5-10 min. Saliva was isolated from the salivettes by centrifugation then stored at $-80^{\circ} \mathrm{C}$. All samples were analysed at the University of Leeds. A commercial ELISA kit (Cozart Bioscience Ltd, Oxfordshire, UK) was used to measure salivary cotinine concentrations, according to the manufacturer's instructions.

\section{Statistical methods}

Derived caffeine intake was expressed in $\mathrm{mg} /$ day averaged over the first trimester (defined as the first 12 weeks of pregnancy) and divided into the 4 weeks before pregnancy, weeks $1-4$, and weeks $5-12$ of the first trimester. Numbers were too small to investigate associations with intake in the second and third trimesters.

Geometric mean caffeine intakes were compared between those pregnancies resulting in late miscarriage or stillbirth and those resulting in a live birth, based on log-transformed caffeine intake in the first trimester.

Unconditional logistic regression modelling was used to predict late miscarriage or stillbirth, with stratification for the two centres, using Stata version 10 survey facilities, [23] adjusting for mother's age, previous history of miscarriage, salivary cotinine concentrations (as a continuous variable measured in $\mathrm{ng} / \mathrm{ml}$ ) and self-reported alcohol consumption, converted into units/day (one unit of alcohol is $10 \mathrm{ml}$ by volume, or $8 \mathrm{~g}$ by weight, of pure alcohol) and categorised as $0,<0.25,0.25-0.5,0.5-1$, and over 1 unit/day.

Tests for linear trend over the continuous measure of caffeine exposure were conducted by inclusion of the uncategorised continuous measure in the models. The robustness of the results to adjustment for nausea was assessed by adding this term to the model. The robustness of the results to adjustment for Index of Multiple Deprivation was also assessed. In addition to adjusting for previous history of miscarriage, the robustness of results to excluding women with previous deliveries was assessed. As a further 
exploration of possible residual confounding by smoking, the models were repeated using self-reported smoking status and amount smoked added to the model. The models were also repeated using caffeine from each of the two main sources, tea and coffee.

\section{Results}

A total of 13,071 eligible women were invited to participate and 2,643 (20\%) consented. Women who had terminations were no longer at risk of miscarriage or stillbirth, and were therefore excluded $(n=8)$. Of the remaining 2,635 pregnancies, 19 resulted in late miscarriage and 9 in stillbirth. The mean (SD) maternal age was 30.0 (6.6) years. The mean pre-pregnant body mass index (SD) was $24.5(4.5) \mathrm{kg} / \mathrm{m}^{2}$. 1,228 $(47 \%)$ of women were primiparous, and 1,324 (51\%) gave birth to boys. In the cohort, 106 (4\%) women went into pre-term labour ( $<37$ weeks gestation) and 67 (3\%) had gestational hypertension (systolic blood pressure over $140 \mathrm{mmHg}$, diastolic blood pressure over $90 \mathrm{mmHg}$, on at least two occasions $30 \mathrm{~min}$ apart) or pre-eclampsia (systolic blood pressure over $140 \mathrm{mmHg}$, diastolic blood pressure over $90 \mathrm{mmHg}$, with proteinuria). The demographic and clinical characteristics are shown in Table 1 according to outcome.

The median (IQR) caffeine intake was 217 (104-366) $\mathrm{mg} /$ day, 183 (74-321) mg/day, and 92 (22-217) mg/day in the 4 weeks before pregnancy, weeks $1-4$, and weeks 512 , respectively. The median (IQR) caffeine intake over the whole first trimester was 132 (58-241) mg/day. The median (IQR) caffeine intake over the whole pregnancy was 134 (63-232) mg/day. In our study, tea contributed more than half of all caffeine consumption during pregnancy [5]. The median (IQR) alcohol intake during the first trimester was 0.2 (0-0.6) units/day, with the highest consumption occurring, as might be expected, pre-pregnancy, and dropping rapidly in the first few weeks.

The geometric mean caffeine intake during the first trimester for women whose pregnancies resulted in a live birth was 103 (95\% CI: 98-108) mg/day. The geometric mean caffeine intake during the first trimester for women whose pregnancies resulted in late miscarriage or stillbirth was 145 (85-249) mg/day.

There was a strong association between caffeine intake in the first trimester and subsequent late miscarriage between 12 and 24 weeks or stillbirth after 24 weeks adjusting for maternal age, parity, alcohol intake and amount smoked measured by salivary cotinine (Table 2). Compared to those consuming $<100 \mathrm{mg} /$ day, the odds ratio for late miscarriage or stillbirth increased to 2.2 (95\% CI: 0.7-7.1) for intakes between 100 and $199 \mathrm{mg} /$ day, to 1.7 (0.4-7.1) for those taking between 200 and $299 \mathrm{mg} /$ day and to 5.1 (1.6-16.4) for those consuming over $300 \mathrm{mg} /$ day $\left(P_{\text {trend }}=0.004\right)$. There were insufficient events to present these separately for late miscarriage and stillbirth. This relationship appeared strongest in relation to caffeine consumption in the first few weeks of pregnancy, though confidence intervals are wide.

The results were unchanged by further adjustment for nausea: Compared to those consuming $<100 \mathrm{mg} /$ day of caffeine during the first trimester, the odds ratio for late miscarriage or stillbirth increased to 2.2 (95\% CI: 0.7-7.1) for intakes between 100 and $199 \mathrm{mg} / \mathrm{day}$, to 1.7 (0.4-7.1) for those taking between 200 and $299 \mathrm{mg} /$ day and to 5.2 (1.6-16.6) for those consuming over $300 \mathrm{mg} /$ day $\left(P_{\text {trend }}=0.004\right)$. When adjusting for Index of Multiple

Table 1 Demographic and clinical characteristics of 2,635 subjects, according to outcome

\begin{tabular}{|c|c|c|c|}
\hline Characteristic & $\begin{array}{l}\text { Late miscarriage } \\
\text { or stillbirth }(n=28)\end{array}$ & $\begin{array}{l}\text { Live birth } \\
(n=2,607)\end{array}$ & $\begin{array}{l}\text { All } \\
(n=2,635)\end{array}$ \\
\hline Mother's mean age (years) (SD) & $30.2(5.0)$ & $30.0(6.6)$ & $30.0(6.6)$ \\
\hline Mother's mean pre-pregnant weight (kg) (SD) & $66.6(13.4)$ & $66.8(13.1)$ & $66.8(13.1)$ \\
\hline Mother's pre-pregnant BMI $\left(\mathrm{kg} / \mathrm{m}^{2}\right)(\mathrm{SD})$ & $24.9(4.3)$ & $24.5(4.5)$ & $24.5(4.5)$ \\
\hline History of previous miscarriage $(\%)$ & $4(14 \%)$ & $611(23 \%)$ & $615(23 \%)$ \\
\hline Gestational hypertension/pre-eclampsia (\%) & $0(0 \%)$ & $67(3 \%)$ & $67(3 \%)$ \\
\hline Mean alcohol intake in 1st trimester (units/day) (SD) & $0.5(0.7)$ & $0.5(0.8)$ & $0.5(0.8)$ \\
\hline \multicolumn{4}{|l|}{ Salivary cotinine concentration $(\mathrm{ng} / \mathrm{ml})(\%)$} \\
\hline$<1 \mathrm{ng} / \mathrm{ml}$ & $19(70 \%)$ & $1,816(73 \%)$ & $1,835(73 \%)$ \\
\hline $1-5 \mathrm{ng} / \mathrm{ml}$ & $5(19 \%)$ & $302(12 \%)$ & $307(12 \%)$ \\
\hline$>5 \mathrm{ng} / \mathrm{ml}$ & $3(11 \%)$ & $364(15 \%)$ & $367(15 \%)$ \\
\hline Child's gender (male) $(\%)$ & $6(32 \%)^{*}$ & $1,318(52 \%)$ & $1,324(51 \%)$ \\
\hline Mean birth weight (g) (SD) & $1,880(1,300)$ & $3,460(540)$ & $3,450(550)$ \\
\hline
\end{tabular}

* Child's gender not recorded for 9 late miscarriages 
Table 2 Odds ratios $(95 \% \mathrm{CI})$ of late miscarriage and stillbirth by caffeine intake categories

\begin{tabular}{|c|c|c|c|c|c|c|c|c|}
\hline & $\begin{array}{l}\text { Caffeine } \\
\text { (mg/day) }\end{array}$ & $\begin{array}{l}\text { No. of } \\
\text { cases/ } \\
\text { total }\end{array}$ & $\begin{array}{l}\text { Unadjusted } \\
\text { OR }\end{array}$ & $(95 \% \mathrm{CI})$ & $P_{\text {trend }}$ & $\begin{array}{l}\text { Adjusted } \\
\text { OR* }\end{array}$ & $(95 \% \mathrm{CI})$ & $P_{\text {trend }}$ \\
\hline \multirow[t]{4}{*}{ Average over 1st trimester } & $<100$ & $6 / 998$ & 1 & - & \multirow[t]{4}{*}{0.04} & 1 & - & \multirow[t]{4}{*}{0.004} \\
\hline & $100-199$ & $7 / 656$ & 1.8 & $(0.6,5.3)$ & & 2.2 & $(0.7,7.1)$ & \\
\hline & $200-299$ & $3 / 402$ & 1.2 & $(0.3,5.0)$ & & 1.7 & $(0.4,7.1)$ & \\
\hline & $300+$ & $9 / 426$ & 3.6 & $(1.3,10.1)$ & & 5.1 & $(1.6,16.4)$ & \\
\hline \multirow[t]{4}{*}{4 weeks before pregnancy } & $<100$ & $3 / 604$ & 1 & - & \multirow[t]{4}{*}{0.002} & 1 & - & \multirow[t]{4}{*}{$<0.001$} \\
\hline & $100-199$ & $5 / 570$ & 1.8 & $(0.4,7.5)$ & & 1.4 & $(0.3,6.3)$ & \\
\hline & 200-299 & $5 / 460$ & 2.2 & $(0.5,9.3)$ & & 2.2 & $(0.5,9.4)$ & \\
\hline & $300+$ & $12 / 870$ & 2.8 & $(0.8,10.0)$ & & 3.0 & $(0.8,10.9)$ & \\
\hline \multirow[t]{4}{*}{ Weeks $1-4$} & $<100$ & $3 / 781$ & 1 & - & \multirow[t]{4}{*}{0.001} & 1 & - & \multirow[t]{4}{*}{$<0.001$} \\
\hline & 100-199 & $5 / 572$ & 2.3 & $(0.5,9.6)$ & & 1.8 & $(0.4,8.2)$ & \\
\hline & 200-299 & $6 / 441$ & 3.6 & $(0.9,14.4)$ & & 3.8 & $(0.9,16.7)$ & \\
\hline & $300+$ & $11 / 706$ & 4.1 & $(1.1,14.8)$ & & 4.7 & $(1.2,18.7)$ & \\
\hline \multirow[t]{4}{*}{ Weeks 5-12 } & $<100$ & $12 / 1,302$ & 1 & - & \multirow[t]{4}{*}{0.6} & 1 & - & \multirow[t]{4}{*}{0.2} \\
\hline & 100-199 & $3 / 497$ & 0.7 & $(0.2,2.3)$ & & 0.8 & $(0.2,3.0)$ & \\
\hline & 200-299 & $6 / 325$ & 2.0 & $(0.8,5.4)$ & & 2.5 & $(0.9,7.0)$ & \\
\hline & $300+$ & $4 / 373$ & 1.2 & $(0.4,3.6)$ & & 1.6 & $(0.5,5.5)$ & \\
\hline
\end{tabular}

* Adjusted odds ratios take account of maternal age, parity, amount smoked (cotinine concentration as a continuous variable, ng/ml) and alcohol intake (categorised as $0,<0.25,0.25-0.5,0.5-1$ and $1+$ units/day). Where numbers do not total to 2,635 , this is due to a small proportion of missing data. A total of 271 women were excluded from adjusted analyses with missing covariate information

Deprivation, again the results were unchanged: Compared to those consuming $<100 \mathrm{mg} /$ day of caffeine during the first trimester, the odds ratio for late miscarriage or stillbirth increased to 2.2 (95\% CI: 0.7-7.0) for intakes between 100 and $199 \mathrm{mg} /$ day, to $1.2(0.2-6.0)$ for those taking between 200 and $299 \mathrm{mg} /$ day and to 5.3 (1.6-to 17.1) for those consuming over $300 \mathrm{mg} / \mathrm{day}\left(P_{\text {trend }}=0.005\right)$. Conclusions were also unchanged when women with previous deliveries were excluded, though confidence intervals were wider than before because of the reduced numbers of cases $\left(P_{\text {trend }}=0.001\right)$. When the model was repeated using selfreported smoking status and amount smoked added to the model, estimates were again very similar: Compared to those consuming $<100 \mathrm{mg} /$ day of caffeine during the first trimester, the odds ratio for late miscarriage or stillbirth increased to 2.3 (95\% CI: 0.7-7.4) for intakes between 100 and $199 \mathrm{mg} /$ day, to $1.7(0.4-7.2)$ for those taking between 200 and $299 \mathrm{mg} /$ day and to 5.3 (1.6-17.4) for those consuming over $300 \mathrm{mg} /$ day $\left(P_{\text {trend }}=0.003\right)$.

Tea and coffee were the dominant sources of caffeine during pregnancy. Results for these sources are presented in Table 3 with caffeine intake categories combined to compare $<200 \mathrm{mg} /$ day with $200+\mathrm{mg} /$ day. Wide confidence intervals reflect the small numbers of cases in the higher intake categories for these sources. The number of women with $>200 \mathrm{mg} /$ day from other sources of caffeine was too low to investigate those sources.

\section{Discussion}

Though the outcomes are rare, we have shown that there is a potentially strong association between caffeine and late miscarriage or stillbirth. Our results of increased late miscarriage and stillbirth with greater caffeine intake add further support to claims of an association between caffeine and negative birth outcomes [8-12, 14]. Many previous studies suffered from the potential for measurement error in the exposure. Our methods minimised the potential for exposure misclassification by including all sources of caffeine, including all caffeine-containing foods, beverages and medications, in a detailed validated questionnaire. Similarly, misclassification of important confounders can lead to bias through residual confounding. In our study, alcohol intake was recorded through the same detailed tool used for caffeine, and the important covariate of smoking status was recorded objectively using salivary cotinine as a biomarker of exposure. Many previous studies, particularly case-control studies, have collected exposure information retrospectively, with the potential for recall bias. However, in our study the exposure was assessed prospectively.

Whilst our study identified only small numbers of late miscarriages and stillbirths, the proportion of pregnancies resulting in these outcomes $(1.1 \%)$ is similar to that found in a large survey of late miscarriage in Canada (0.6\%) [24]. However, the small number of events limited our power to 
Table 3 Odds ratios (95\% CI) of late miscarriage and stillbirth by tea and coffee intake categories

\begin{tabular}{|c|c|c|c|c|c|c|c|c|}
\hline & Caffeine (mg/day) & No. of cases/total & Unadjusted OR & $(95 \% \mathrm{CI})$ & $P_{\text {trend }}$ & Adjusted OR* & $(95 \% \mathrm{CI})$ & $P_{\text {trend }}$ \\
\hline \multirow[t]{2}{*}{ Tea } & $<200$ & $17 / 2,021$ & 1 & - & 0.07 & 1 & - & 0.02 \\
\hline & $200+$ & $8 / 500$ & 1.9 & $(0.8,4.5)$ & & 2.2 & $(0.9,5.4)$ & \\
\hline \multirow[t]{2}{*}{ Coffee } & $<200$ & $24 / 2,414$ & 1 & - & 0.4 & 1 & - & 0.3 \\
\hline & $200+$ & $1 / 107$ & 0.9 & $(0.1,7.0)$ & & 1.2 & $(0.1,9.4)$ & \\
\hline
\end{tabular}

* Adjusted odds ratios take account of maternal age, parity, amount smoked (cotinine concentration as a continuous variable, ng/ml) and alcohol intake (categorised as $0,<0.25,0.25-0.5,0.5-1$ and $1+$ units/day). Where numbers do not total to 2,635 , this is due to a small proportion of missing data. A total of 271 women were excluded from adjusted analyses with missing covariate information

investigate subgroups, and resulted in very wide confidence intervals for the estimates. Our findings therefore need further replication in larger prospective population-based studies. Our response rate $(20 \%)$ was disappointing and reflects the demanding requirements of the study. For ethical reasons responders could not be compared to nonresponders. However, mean birth weights for gestational age, rates of late miscarriage and stillbirth, and caffeine intakes were comparable to those found in other studies [24-26]. In addition, there is no reason to assume that caffeine metabolism phenotype should differ between responders and non-responders, other than in those confounders that we have adjusted for, e.g. smoking status.

Whilst it has been suggested that the relationship between caffeine and miscarriage or stillbirth is confounded by nausea, [8, 27] which may lead to both a reduction in caffeine intake and risk to the foetus, we consider that nausea is more likely to be either a marker for a healthy pregnancy, rather than causative, or that caffeine intake may lead to nausea in some.[8, 27, 28] Wherever nausea lies on the causal pathway, analyses both with and without adjustment for nausea gave very similar results that did not alter the conclusions. In addition, we found an association with caffeine intake before pregnancy, which could not be influenced by physiological changes and processes during pregnancy (such as slowing caffeine metabolism and increasing the half life of serum caffeine).

It may be that higher caffeine intake increases risk of late miscarriage in susceptible women. A case-control study of women with recurrent pregnancy loss found a statistically significantly increased risk of pregnancy loss only in women with the homozygous (A/A) genotype representing the high inducibility genotype for CYP1A2, which increases the rate of caffeine metabolism [29]. Studies in monkeys have shown a high rate of stillbirths and miscarriage with maternal caffeine intakes of $10-15 \mathrm{mg} / \mathrm{kg}$ body weight per day given via the drinking water, though experimental research such as this tends to provide evidence at doses of exposure that are not relevant to most human populations. For example, this is equivalent to a $60 \mathrm{~kg}$ woman consuming 8-12 average cups of coffee per day (assuming $75 \mathrm{mg}$ caffeine/cup). Interestingly, the main serum metabolite of caffeine in monkeys is theophylline, whereas in humans it is paraxanthine. The comparative toxicities of these two metabolites is unknown [16]. Klebanoff et al. using paraxanthine as a marker for caffeine intake, found an increased risk of late miscarriage only for very high intakes, [13] though it is unclear whether it is caffeine, paraxanthine, or another caffeine metabolite that is the potentially causative agent.

\section{Conclusion}

Our study identified only small numbers of late miscarriages and stillbirths, limiting power to detect small associations, and resulting in very wide confidence intervals. Therefore, although reaching statistical significance, there is considerable uncertainty in the size of the association. However, given the careful methodology employed, and the advances over some earlier studies, our findings make a valuable contribution to the literature in this field. Given also the paucity of randomised controlled trials in this area, and the practical and ethical difficulties in conducting them, our study strengthens the observational evidence base on which current guidance is founded.

Acknowledgments This research was funded by the Food Standards Agency (Contract T01032/33). We thank Stuart Creton, Clifton Gay, Gordon Gibson, David Gott, Fred Kadlubar, Mark Klebanoff Caroline Tahourdin, and Natalie Thatcher for their useful comments during the study., Heather Ong, Vilas Misty, Clare Lawrence, Chetan Ghandi, Bhavin Daudia, Sue Chell, and the Department of Chemical Pathology, University Hospitals of Leicester NHS Trust, for sample handling and processing.

\section{Appendix}

Contribution to authorship

Darren C. Greenwood conceived the paper, performed and interpreted statistical analyses, and wrote the manuscript. Principal Investigators were Janet E. Cade (Leeds) and Marcus S. Cooke (Leicester). Co-Investigators were Nigel Simpson, James Walker, Christopher P. Wild (Leeds) and 
Justin C. Konje (Leicester). All authors were given the opportunity to comment on and approve the paper.

Members of the CARE Study Group are:

Clinicians: Nisreen Alwan, Nigel Simpson (Co-Investigator), James Walker (Co-Investigator) (Leeds); Justin C. Konje

(Co-Investigator), Neelam Potdar (Leicester).

Nutritionists: Sinead Boylan (PhD student), Janet E. Cade (Principal Investigator), Sara F.L. Kirk (Co-Investigator) (Leeds).

Laboratory methods: Alastair W.M. Hay, Susan Shires, Kay L.M. White, Christopher P. Wild (Co-Investigator) (Leeds); Marcus S. Cooke (Principal Investigator) (Leicester).

Statisticians: Darren C. Greenwood (Co-Investigator)(Leeds); Nicholas Taub (Leicester).

Research midwives: Vivien A. Dolby (Leeds), Karen

C. Chipps, Shabira Kassam (Leicester).

Database managers: James D. Thomas (Leeds); Jim Charvill (Leicester).

\section{References}

1. Goldstein A, Warren R. Passage of caffeine into human gonadal and fetal tissue. Biochem Pharmacol. 1962;11:166-8.

2. Morris MB, Weinstein L. Caffeine and the foetus: is trouble brewing? Am J Obstet Gynecol. 1981;140:607-10.

3. Kirkinen P, Jouppila P, Koivula A, Vuori J, Puukka M. The effect of caffeine on placental and fetal blood flow in human pregnancy. Am J Obstet Gynecol. 1983;147:939-42.

4. Martin TR, Bracken MB. The association between low birth weight and caffeine consumption during pregnancy. Am J Epidemiol. 1987;126:813-21.

5. Boylan S, Cade JE, Dolby VA, Greenwood DC, Hay AWM, Kirk SFL, et al. Maternal caffeine intake during pregnancy, risk of fetal growth restriction: a large prospective observational study. BMJ. 2008;337:a2332.

6. Bracken MB, Triche EW, Belanger K, Hellenbrand K, Leaderer BP. Association of Maternal Caffeine Consumption with Decrements in Fetal Growth. Am J Epidemiol. 2003;157:456-66.

7. Bech BH, Obel C, Henriksen TB, Olsen J. Effect of reducing caffeine intake on birth weight and length of gestation: randomised controlled trial. BMJ. 2007;334:409.

8. Wen W, Shu XO, Jacobs DR Jr, Brown JE. The associations of maternal caffeine consumption and nausea with spontaneous abortion. Epidemiology. 2001;12:38-42.

9. Tolstrup JS, Kjaer SK, Munk C, Madsen LB, Ottesen B, Bergholt $\mathrm{T}$, et al. Does caffeine and alcohol intake before pregnancy predict the occurrence of spontaneous abortion? Hum Reprod. 2003;18:2704-10.

10. Khoury JC, Miodovnik M, Buncher CR, Kalkwarf H, McElvy S, Khoury PR, et al. Consequences of smoking and caffeine consumption during pregnancy in women with type 1 diabetes. J Matern Fetal Neonatal Med. 2004;15:44-50.

11. Weng X, Odouli R, Li DK. Maternal caffeine consumption during pregnancy and the risk of miscarriage: a prospective cohort study. Am J Obstet Gynecol. 2008;198:279.

12. Mills JL, Holmes LB, Aarons JH, Simpson JL, Brown ZA, Jovanovic-Peterson LG, et al. Moderate caffeine use and the risk of spontaneous abortion and intrauterine growth retardation. J Am Med Assoc. 1993;269:593-7.

13. Klebanoff MA, Levine RJ, DerSimonian R, Clemens JD, Wilkins DG. Maternal serum paraxanthine, a caffeine metabolite, and the risk of spontaneous abortion. N Engl J Med. 1999;341:1639-44.

14. Savitz DA, Chan RL, Herring AH, Howards PP, Hartmann KE. Caffeine and Miscarriage Risk. Epidemiology. 2008;19:55-62.

15. Committee on Toxicity of Chemicals in Food. Consumer products and the environment. Statement on the review of caffeine. Department of Health; 1984.

16. Committee on Toxicity of Chemicals in Food CPatE. Statement on the reproductive effects of caffeine. Food Standards Agency; 2001.

17. Committee on Toxicity of Chemicals in Food CPatE. Statement on the reproductive effects of caffeine. Food Standards Agency; 2008.

18. Organisation of teratology information specialists. Caffeine and pregnancy; 2006.

19. American College of Obstetricians and Gynecologists. Education pamphlet AP001-nutrition during pregnancy. Washington, DC: American College of Obstetricians and Gynecologists; 2008.

20. Boylan SM, Cade JE, Kirk SFL, Greenwood DC, White KLM, Shires S, et al. Assessing caffeine exposure in pregnant women. Br J Nutr. 2008;100:875-82.

21. Ministry of Agriculture Fisheries and Food. Survey of caffeine and other methylxanthines in energy drinks and other caffeinecontaining products (updated). Report no.: 144. London: Ministry of Agriculture, Fisheries and Food; 1998.

22. Cade JE, Burley VJ, Greenwood DC. The UK Women's Cohort Study: comparison of vegetarians, fish- eaters and meat-eaters. Public Health Nutr. 2004;7:871-8.

23. StataCorp. Stata statistical software: Release 10.1. College Station, TX: Stata Corporation; 2007.

24. Wyatt PR, Owolabi T, Meier C, Huang T. Age-specific risk of fetal loss observed in a second trimester serum screening population. Am J Obstet Gynecol. 2005;192:240-6.

25. Gardosi J. Customized fetal growth standards: rationale and clinical application. Semin Perinatol. 2004;28:33-40.

26. Rosenberg L, Mitchell AA, Shapiro S, Slone D. Selected birth defects in relation to caffeine-containing beverages. J Am Med Assoc. 1982;247:1429-32.

27. Fenster L, Eskenazi B, Windham GC, Swan SH. Caffeine consumption during pregnancy and spontaneous abortion. Epidemiology. 1991;2:168-74.

28. Stein Z, Susser M. Miscarriage, caffeine, and the epiphenomena of pregnancy: the causal model. Epidemiology. 1991;2:163-7.

29. Sata F, Yamada H, Suzuki K, Saijo Y, Kato EH, Morikawa M, et al. Caffeine intake, CYP1A2 polymorphism and the risk of recurrent pregnancy loss. Mol Hum Reprod. 2005;11:357-60. 